\title{
Psychiatric co morbidities in ESRD Patients Recently Placed on Haemodialysis : A Prospective Observational Study from a Tertiary Care Hospital
}

Sarwar Iqbal ${ }^{*}$, Umme Salma Talukder ${ }^{2 *}$, Tufayel Ahmed Chowdhury ${ }^{3}$, Md. Mostarshid Billah ${ }^{4}$, Mehruba Alam Ananna ${ }^{5}$, Muhammad Abdur Rahim 5 , Tabassum Samad ${ }^{6}$, Wasim Md. Mohosinul Haque ${ }^{7}$, Mohammad Omar Faruq ${ }^{8}$

\begin{abstract}
Background: Psychiatric co-morbidity especially anxiety and depression are common in patients who are recently placed on dialysis, but very little research has been done on this subject. Mental illness results in increased non-compliance in accepting dialysis and this results in increased mortality in End Stage Renal Disease (ESRD) patients.

Methodology: This cross- sectional study was done on ESRD patients newly diagnosed and initiated hemodialysis in the department of Nephrology of Bangladesh Institute of Research and Rehabilitation in Diabetes, Endocrine and Metabolic Disorders (BIRDEM), Dhaka, Bangladesh with informed written consent and maintaining privacy. Diagnostic and Statistical Manual of Mental Disorders (DSM-V) was used for diagnosis of psychiatric disorders. Patients on maintenance hemodialysis for more than 1 month and patients on Chronic Ambulatory Peritoneal Dialysis were excluded in this study.

Results: There were total 83 patients out of whom there were 50 (62.2\%) males and 33(39.38\%) females. Mean age of study patients was $56.8 \pm 9.96$ years. Bulk of the patients was clinically depressed (68.7\%), followed by anxiety disorder (13.3\%) rest were acute stress disorder, adjustment disorder and one case of psychosis. $8.4 \%$ participants denied any symptoms.

Conclusion: Significant psychiatric co-morbidities developed in newly diagnosed ESRD subjects when they were prescribed hemodialysis. This study showed majority of the patients with renal failure on initiating hemodialysis who develop different psychiatric problems that need prompt diagnosis and appropriate treatment. These interventions will improve the quality of life of ESRD patients.
\end{abstract}

Key words: Major Depressive Disorder (MDD), Anxiety Disorder (AD), Acute Stress Disorder, Adjustment Disorder, Psychosis, End Stage Renal Disease (ESRD)

Introduction :

There are approximately two million patients suffering from ESRD worldwide regularly receive renal replacement therapy (RRT) in the form of dialysis (hemodialysis and peritoneal dialysis). Data from hospitals of urban population based and under privileged population based studies suggest that there is a chronic kidney diseases (CKD) prevalence of $16-18 \%$ in Bangladesh ${ }^{1}$.

Approximately 800 patients are enrolled for hemodialysis in BIRDEM every year. ${ }^{2}$ As per literature nine percent of all hospitalised patients receiving dialysis present with mental disorder ${ }^{3}$. Hospitalisation with mental disorders is 1.5 to 3 times higher for renal failure patients compared with other chronically ill patients. Depression, anxiety, alcohol and drug abuse are the common co-morbidities found in patients going through dialysis. Dementia and drug related disorders are also found $^{3-5}$. A qualitative study by Gregosy et al found patients with ESRD receiving hemodialysis developed a new identity and sense of self. This new and evolving emotional /psychological state indicated that patient's became cognisant of a new set of circumstances with an uncertain future and demands of illness, dependence on machinery, medication and health care providers ${ }^{6}$. Remarkable advances in the understanding and treatment of ESRD have been achieved over the last 20 years. However, most of the investigations have focused on medical factors like anemia, nutritional status, adequacy of dialysis, etc. which are commonly observed features. During recent years, there has been increasing attention given to the individual characteristics of patient with an emphasis placed on understanding the effects of dialysis on the patient's social situation, perceptions and responses to the illness. The impact of dialysis on patients physicians and healthcare providers and on their spouses, families and patients socioeconomic status have also been taken into consideration. Although this area of "psycho-nephrology" has been a subject of research for many years, recent work on patients with and without renal disease has advanced our understanding of the interaction of psychological factors with medical outcomes. Few studies have tracked psychosocial responses longitudinally in patients treated for ESRD and linked these responses with outcome. Almost no data exist regarding examining psychosocial factors in patients with chronic renal insufficiency, which predict subsequent outcome in ESRD. Differences between outcomes of ESRD patients should be assessed for variations in family structure, social structure, and extent of perceived social support. Stress mediators should be evaluated at 
baseline and longitudinally in studies of patients with ESRD in which morbidity and mortality are outcomes ${ }^{7}$. Few studies have estimated incidence of psychiatric illness in dialysis patients worldwide and so far there is no study done in Bangladesh. Therefore this study investigates the occurrences of psychiatric morbidity in Bangladeshi ESRD patients on whom hemodialysis has been initiated.

\section{Methodology:}

This cross-sectional survey was done (for one year) between January 2015 and December 2015 on 83 consecutive newly detected ESRD patients who were prescribed hemodialysis, after being admitted in department of nephrology inpatient unit in Bangladesh Institute of Research and Rehabilitation in Diabetes, Endocrine and Metabolic Disorders (BIRDEM) hospital. Patients with prior history or family history of psychiatric illness of all ages taking dialysis were excluded. Patients on hemodialysis for more than 1 month and patients on Continuous Ambulatory Peritoneal Dialysis were also excluded. Convenient sampling was done after informed consent of the patient and his attendant. Psychiatric diagnosis was made according to Diagnostic and Statistical Manual of Mental Disorders (DSM-V) by face-to-face interview. Socio-demographic data was collected by a structured questionnaire.

1. Dr. Sarwar Iqbal, MD (Nephrology), Associate professor \& Head, Dept. of Nephrology, BIRDEM General Hospital, Dhaka, Bangladesh

2. Dr. Umme Salma Talukder, FCPS (Psychiatry), Assistant professor, Dept. of Psychiatry, BIRDEM General Hospital, Dhaka, Bangladesh

3. Dr. Tufayel Ahmed Chowdhury, FCPS (Medicine), Registrar (in charge), Dept. of Nephrology, BIRDEM General Hospital, Dhaka, Bangladesh

4. Dr. Md. Mostarshid Billah, FCPS (Medicine), Junior Consultant, Dept. of Nephrology \& Dialysis, BIRDEM General Hospital, Dhaka, Bangladesh

5. Dr. Mehruba Alam Anana, Dr. Muhammad Abdur Rahim, FCPS (Medicine), Assistant Professor, Dept. of Nephrology, BIRDEM General Hospital, Dhaka, Bangladesh

6. Dr. Tabassum Samad, FCPS (Medicine), Junior Consultant, Dept. of Nephrology, BIRDEM General Hospital, Dhaka, Bangladesh

7. Dr. Wasim Md. Mohosinul Haque, FCPS (Medicine), Associate Professor, Dept. of Nephrology, BIRDEM General Hospital, Dhaka, Bangladesh

8. Professor Mohammad Omar Faruq, Professor of Critical Care Medicine, Ibn Sina Hospital, Dhanmondi, Dhaka, Bangladesh

Corresponding Author :

1. Dr. Sarwar Iqbal, MD (Nephrology), Associate professor \& Head, Dept. of Nephrology, BIRDEM General Hospital, Dhaka, Bangladesh Email: sarwariqbal2003@yahoo.com

2. Dr. Umme Salma Talukder, Assistant Professor, Department of Psychiatry, Ibrahim Medical College and BIRDEM General hospital. E mail: safiy3@gmail.com

* Both the authors had the main contributions in this study.
Chronic Kidney Disease (CKD), previously termed chronic renal failure, refers to an irreversible deterioration in renal function, which usually develops over a period of years. When death is likely without Renal Replacement Therapy (CKD stage 5), it is called end-stage renal disease or failure (ESRD or ESRF) ${ }^{8}$.

According to DSM-V the key features of Major Depressive Disorder are depressed mood and loss of interest or pleasure for at least 2 weeks. These includes significant weight loss when not dieting or weight gain, insomnia or hypersomnia and psychomotor retardation or agitation, fatigue, loss of energy, feelings of worthlessness, excessive or inappropriate feeling of guilt, diminished ability to think or concentrate and suicidal ideation or suicidal attempt ${ }^{9}$.

One remarkable finding may be the first onset of psychosis without prior psychiatric treatment or family history of psychiatric illness. Patients may have typical features of schizophrenia like delusion of persecution, auditory hallucination, disorganised behaviour like violence and disorganised speech and non-complaint to drugs. These cases are defined as first-episode-psychosis responded to injectable and oral antipsychotics in a short time'. On the long run these patients are diagnosed as Schizophrenia.

DSM-V defined anxiety disorder as apprehensive expectation with other psychological and physical feature like restlessness, difficulty in concentrating, muscle tension and sleep disturbances for more than at least 6 months .

Conversion Disorder is defined as one or more symptoms of altered voluntary motor or sensory function. Clinical findings provide evidence of incompatibility between the symptoms and recognised neurological or medical conditions. The symptom or deficit is not better explained by another medical or mental disorder. Dissociative symptoms are usually associated with conversion disorder. Dissociation is defined as an inability to recall important autobiographical information, usually of a traumatic or stressful nature that is inconsistent with ordinary forgetting. The symptom or deficit causes clinically significant distress or impairment in social, occupational or other important areas of functioning or warrant medical evaluation ${ }^{8}$.

Adjustment disorder is the development of emotional or behavioural symptoms in relation to an identifiable stressor(s) occurring within 3 months of the onset of the stressor(s). These symptoms or behaviours are clinically significant, as evidenced by one or both of the following. Marked distress that is out of proportion to the severity or intensity of the stressor, taking into account the context, external and cultural factors that might influence symptoms and severity and presentation. Patients will have significant impairment in social, occupational or other important areas of functioning. Once the stressor or its consequences have terminated, the symptoms do not persist for more than an additional 6 months

Acute stress disorder occurs due to exposure to actual or threatened death, serious injury, or sexual violation in one or more of the followings ways, for example directly 
Bangladesh Crit Care J March 2016; 4 (1): 28-32

experiencing the traumatic events, witnessing in person, the events as it occurred to others. Learning that the events occurred to a close one. Experiencing repeated exposure to aversive details. Symptom presentations are like intrusion, negative mood, dissociation, avoidance and arousal, beginning or worsening after the traumatic event(s) occured ${ }^{9}$.

\section{Statistical Analysis :}

SPSS version 20.0 was used to analyze data. Socio demographic data was expressed as frequency with corresponding percentage. Statistical data on psychiatric co morbidity was expressed as frequency and was compared between male and female and age group above and below 50 years using chi-square $\left(\mathrm{x}^{2}\right)$. Age of patients was expressed as mean and standard deviation from the mean. Level of significance was set at $5 \%$ or 0.05 and $p<0.05$ was considered significant.

\section{Results :}

There were 83 total study populations. Among them there were 50(60.2\%) males and 33(39.8\%) females. Mean age was $56.8 \pm 9.96$ years (Age range $25-75$ years). Majority $(97.6 \%$ ) of the respondents were married and from urban area (65.1\%). Different occupational groups were found out of which 39.8\% were housewives. Other socio-demographic data are shown in the Table I. Table II shows psychiatric co morbidity according to gender distribution and Table III shows psychiatric co morbidity according to age distribution.

Table I

\begin{tabular}{|c|c|c|c|c|}
\hline Variables & Frequency & Percentage & Mean & SD \\
\hline Age & & & 56.9 & 9.96 \\
\hline \multicolumn{5}{|l|}{ Gender } \\
\hline Male & 50 & 60.2 & & \\
\hline Female & 33 & 39.8 & & \\
\hline \multicolumn{5}{|l|}{ Marital Status } \\
\hline Married & 81 & 97.6 & & \\
\hline Unmarried & 2 & 2.4 & & \\
\hline \multicolumn{5}{|l|}{ Residence } \\
\hline Urban & 54 & 65.1 & & \\
\hline Rural & 20 & 24.1 & & \\
\hline Semi urban & 9 & 10.8 & & \\
\hline \multicolumn{5}{|l|}{ Occupation } \\
\hline Not earning & 40 & 48.19 & & \\
\hline Service holder & 23 & 27.7 & & \\
\hline Retired & 7 & 8.4 & & \\
\hline Businessman & 13 & 15.7 & & \\
\hline \multicolumn{5}{|l|}{ Education } \\
\hline Class 1 to 4 & 7 & 8.4 & & \\
\hline Below SSC* & 32 & 38.6 & & \\
\hline $\mathrm{HSC}^{* *}$ & 14 & 16.9 & & \\
\hline Graduated from College & 20 & 24.1 & & \\
\hline
\end{tabular}

*SSC: Secondary School Certificate

**HSC: Higher Secondary Certificate
Table II

\begin{tabular}{lcccc}
\hline Psychiatric disorder & \multicolumn{3}{c}{ Sex } & p value \\
\hline & Male & Female & Total & \\
AD* & 8 & 3 & $11(13.3 \%)$ & 0.56 \\
MDD** & 33 & 24 & $57(68.7 \%)$ & 0.68 \\
Adjustment Disorder & 2 & 2 & $4(4.8 \%)$ & 0.92 \\
Acute stress Disorder & 1 & 0 & $1(1.2 \%)$ & 0.66 \\
First episodes of psychosis & 0 & 2 & $2(2.4 \%)$ & 0.30 \\
Conversion disorder & 0 & 1 & $1(1.3 \%)$ & 0.66 \\
No Psychiatric Comorbidity & 6 & 1 & $7(8.4 \%)$ & 0.30 \\
Total & 50 & 33 & $83(100 \%)$ & \\
\hline
\end{tabular}

$* \mathrm{AD}=$ Anxiety Disorder

$* * \mathrm{MDD}=$ Major depressive disorder

Table III

\begin{tabular}{lcccc}
\hline & Age in years & & Total & p value \\
\hline & $<50$ yrs & $\geq 50$ yrs & & \\
AD* & 2 & 9 & $11(13.3 \%)$ & 0.90 \\
MDD** & 15 & 42 & $57(68.7 \%)$ & 0.67 \\
No Psychiatric Co morbidity & 2 & 5 & $7(8.4 \%)$ & 0.86 \\
Adjustment Disorder & 1 & 3 & $4(4.8 \%)$ & 0.57 \\
Acute stress Disorder & 0 & 1 & $1(1.2 \%)$ & 0.54 \\
First episodes of psychosis & 0 & 2 & $2(2.4 \%)$ & 0.97 \\
Conversion disorder & 0 & 1 & $1(1.2 \%)$ & 0.54 \\
Total & 20 & 63 & 83 & \\
\hline
\end{tabular}

$* \mathrm{AD}=$ Anxiety Disorder

**MDD= Major depressive disorder

Among the psychiatric co-morbidity major depressive disorder was found to be commonest $(68.7 \%)$ in number and was followed by anxiety disorder (13.3\%) (Table II and Table III). $8.4 \%$ respondents were found to have no psychiatric comorbidity.

\section{Discussion :}

Psycho-nephrology refers to the psychological problems and their management related to kidney disorders such as depression, anxiety, sexual problems, psychosis, suicide, delirium, substance abuse and alcoholism, problems in rehabilitation, maladjustment due to dependency etc. Recently, work on patients with renal diseases has advanced the understanding of the effect of the interaction of psychosocial and biological factors on the outcome ${ }^{10,11}$. Patients taking dialysis manifested varied psychiatric disorders, mainly major depressive disorder, anxiety disorder, 
acute stress disorder, adjustment disorder, conversion and dissociative symptoms and even a very few cases of first episode psychosis which strongly indicates the overwhelming stress associated with dialysis and the urgent need of psychiatric intervention when needed ${ }^{12}$.

In our study physical complaints like loss of appetite, fatigue etc. was carefully monitored to exclude organic cause. Most of the patients taking dialysis usually end up being clinically depressed sooner or later. In a study ${ }^{13}$ on 241 maintenance haemodialysis (MHD) patients in Boston (USA) area, $57(23.7 \%)$ participants with significant depressive symptoms were found but we found depressive illness in $68.7 \%$ of our study patients.

Cukor et $\mathrm{al}^{14}$ observed that $29 \%$ of study patients on dialysis had current depressive disorder and $27 \%$ had a current major anxiety disorder. In the same study substance abuse was found in $19 \%$ and $10 \%$ of study patients had a psychotic disorder. In our study current anxiety disorder was found in $13.3 \%$ and first episode of psychosis was found in $2.4 \%$ (one case only). There was no substance abuse disorder in our study.

There are recent estimates of a $20-30 \%$ incidence of depressive disorders in hemodialysis populations in the study of Cukor et $\mathrm{al}^{14}$. Depression is second only to hypertension in frequency as a co-morbid diagnosis in patients with ESRD, yet it is under investigated and seldom identified or treated adequately in hemodialysis patients. Further more, depression has been associated with impaired recovery and increased mortality in many diseases and specifically in ESRD in the same study ${ }^{14}$.

Studies ${ }^{13-16}$ have shown that ESRD has been associated with add-on stress. The associated psychological and sociological factors add to the stress in addition to the underlying chronic disease. A number of psychosocial problems like loss of freedom due to dependency on machine, marital and social adjustment problems, deterioration in psychomotor performances, mental functions and perceptual performances add on to lead to an anxiety state. Extreme anxiety and psycho somatic symptoms such as breathlessness, palpitations, chest pain, sweating and fear of dying may occur in renal failure cases. Many a times, these symptoms are not associated with any triggers and may occur unexpectedly. There are, on the other hand, many reasons regarding the occurrence of anxiety. The process of dialysis and a multitude of potential medical complications give the patient a lot to worry and anticipate about. Renal failure patients have been noted as the biggest deniers of psychiatric symptoms. They often feel that they are over attended by doctors and motivational psychotherapy is often best administered in the dialysis unit itself by doctors and other staff. Many patients on dialysis do well if individual psychotherapy is administered during the dialysis sessions.

Another psychiatric presentation is the non-adherence to the treatment and medical regimens. Such patients take appointments, but do not visit the doctor and may also get angry on the staff of the dialysis unit. The dialysis population is not just a cross section of the general population and this group is skewed in the direction of the noncompliant diabetic, noncompliant hypertensive and also the alcoholic. These patients often express their anger as they feel unlike many others they are unable to lead a normal life, as they have to suffer and undergo repeated medical procedures. Denial of death is also a common problem in such patients who become much sicker. Mental health professionals are often being needed in such cases to provide end-stage counselling and psychotherapy.

There was only one case of conversion disorder among our study patients. The patient was married female in her late $40 \mathrm{~s}$ and she could recognise all her family members including children with exception of her husband. Mental status examination revealed that she was stubborn in nature and was non-complaint with dialysis. She was forcibly admitted by her husband in the hospital and was forced to take hemodialysis. This resulted in her internal conflict that she was unable to cope with her physical illness requiring dialysis and the symptom of not recognising her husband was a manifestation of her unconscious feeing against her husband.

One interesting aspect of findings in our study was the lack of substance abuse, alcoholism and suicidal tendency. Such co morbidities are quite common in the studies done out side Bangladesh ${ }^{17}$. This indicates the high resilience and coping skills of Bangladeshi people resulting from their closely-knit social and religious background. Moreover family members e.g. wives and children were the primary care givers of ESRD patients in our society.

In our study there was no statistical deference in mental illness between males and females. But worldwide, women are about twice as likely to experience depression as males ${ }^{18}$. There is no statistical difference noted between age group above 50 years and age group below 50 years in our study. $8.4 \%$ of our study patients denied any mental symptom. But in our observation, these patients or their families were already stressed from dialysis procedure and were uncooperative. Few of the exceptional patients appeared resilient and effectively coped with the dialysis procedure.

There were a few limitations of our study. Our study sample was small and study duration was short. Stigma against psychiatric illness was a major setback during psychiatric evaluation. It became necessary to ask questions regarding sexual health problems with proper consent and privacy. It was sometimes necessary to exclude organic mental disorder by doing brain imaging but could not be done to establish diagnosis of psychiatric co morbidity. These were few other limitations of our study.

This study is the first of its kind in Bangladesh done on ESRD patients. A larger study sample involving several centers with longer study duration would make the study more representative of our population.

\section{Acknowledgement :}

We express great appreciation to Prof. Anwara Begum, Head, Dept. of Psychiatry, BIRDEM General Hospital for her assistance, inspiration and supervision of our study. 


\section{References :}

1. Rashid H U. Management of End Stage Renal Disease-Bangladesh Perspective. The Open Urology \& Nephrology Journal. 2014 ;( 7):108-12.

2. Haemodialysis Unit . Statistical year book 2012-2013. Diabetic Association of Bangladesh: 156-57.

3. Kimmel P L, Thamer M, Richard C M, Ray N F. Psychiatric Illness in Patients with End-stage Renal disease 1998;105 (3):214-21.

4. Gupta M, Annadatha S. Treating Bipolar Disorder in Patients with Renal Failure having Haemodialysis. Clin Pract and Epi Mental Health $2008 ;(4): 21$.

5. Racy T, Lea H. Mental Health May Play a Role in Dialysis Patients' Survival. Clin Jr Am Soc Neph Mar 30 Clinical Journal of the American Society Nephrology(doi:10.2215/CJN.06730711).

6. John J F, ThomasVJ. The Psychosocial Experience of Patients with End-Stage Renal Disease and Its Impact on Quality of Life: Findings from a Needs Assessment to Shape a Service. ISRN Nephrology, 2013; 8

7. Cukor D, Cohen SD, Peterson RA, Kimmel PL. Psychosocial aspect of chronic disease: ESRD as a paradigmatic Illness. Jr Am Soc of Neph Nov 2007; 12(18):3042-55. .

8. Gouddard J, A.N. Turn AN. Kidney and Urinary tract Disease. Walker B.R., College N.R, Ralston S.H.,Penman I. D, editors. Davidson's Principles and Practice of Medicine 22nd edition. Edinburgh: Churchill Livingstone Elsivier, 2014; 461-523.

9. American Psychiatric Association Diagnostic and Statistical Manual of Mental Disorders,Fifthedition. Arlington,VA, American Psychiatric Assocuation,2013.pg50-163.

10. Levy NB. What is Psychonephrology? J Nephrol . 2008: 21:S51-3.
11. Kimmel PL.Deprtession in Patients with chronic renal disease . What we know and what we need to know .J Psychosom Res. 2002:53:951-6.

12. Glick ID. Goldfield MD, Kovnat PJ: Recognition and management of psychosis associated with hemodialysis. Calif Med .1973; 119:56-59.

13. Tighiouart H, Griffith JL, and Sarnak MJ .Depression and Cognitive Function in Maintenance Hemodialysis Patients. Am J Kidney Dis. 2010 October; 56(4):704-12.

14. Cukor D, Coplan J, Brown C, Friedman S, Cromwell-Smith A, Peterson R A, Kimmel P L. Depression and Anxiety in Urban Hemodialysis Patients. Clin J Am Soc Nephrol 2007; 2:484-90.

15. Kohli S, Batra P, and Aggarwal H K .Anxiety, locus of control, and coping strategies among end-stage renal disease patients undergoing maintenance hemodialysis. Indian J Nephrol. 2011;21(3):177-81.

16. Taskapan H, Fehmi A, Murat K B, Emul M, Mine K, Taskapan C, Sahin I. Psychiatric disorders and large inter-dialytic weight gain in patients on chronic haemodialysis. Nephrology 2005; 10:15-20.

17. De Sousa, Brian T. Agganis, MA, Daniel E, Weiner, Lena M, Giang,Scott T. Psychiatric issues in renal failure and dialysis. Indian J Nephrol. 2008; 18(2): 47-50.

18. Stephanie F. Health Line Depression statistics. www. healthline.com /health/ depression/ statistics - March 28, 2012 